\title{
Integration and calibration of a conceptual rainfall-runoff model in the framework of a decision support system for river basin
} management

\author{
J. Götzinger and A. Bárdossy \\ Institute for Hydraulic Engineering, Universitaet Stuttgart, Germany \\ Received: 7 January 2005 - Revised: 1 August 2005 - Accepted: 1 September 2005 - Published: 16 December 2005
}

\begin{abstract}
Water balance models provide significant input to integrated models that are used to simulate river basin processes. However, one of the primary problems involves the coupling and simultaneous calibration of rainfall-runoff and groundwater models. This problem manifests itself through circular arguments - the hydrologic model is modified to calculate highly discretized groundwater recharge rates as input to the groundwater model which provides modeled base flow for the flood-routing module of the rainfall-runoff model. A possibility to overcome this problem using a modified version of the HBV Model is presented in this paper. Regionalisation and optimization methods lead to objective and efficient calibration despite large numbers of parameters. The representation of model parameters by transfer functions of catchment characteristics enables consistent parameter estimation. By establishing such relationships, models are calibrated for the parameters of the transfer functions instead of the model parameters themselves. Simulated annealing, using weighted Nash-Sutcliffe-coefficients of variable temporal aggregation, assists in efficient parameterisations. The simulations are compared to observed discharge and groundwater recharge modeled by the State Institute for Environmental Protection Baden-Württemberg using the model TRAIN-GWN.
\end{abstract}

\section{Introduction}

The European Union Water Framework Directive introduces interdisciplinary and holistic considerations for entire river basins. Therefore, decision support systems that integrate water balance models are necessary to establish river basin management plans. The EU-funded project, RIVERTWIN, aims at refining, testing and implementing an integrated regional model to facilitate water resource management in twinned river basins having contrasting ecological, social

Correspondence to: J. Götzinger

(jens.goetzinger@iws.uni-stuttgart.de) and economic conditions. A consortium of 14 partners provides a cornerstone in the RIVERTWIN project. Partners represent agro-economy, land use, groundwater, water demand, surface water, water quality, fish ecology and other disciplines pertinent to river basin management. These multidiscipline partners work together in order to bridge acknowledged gaps between the three primary concerns addressed by river basin management. These concerns include economy, land use, and water management. To better achieve the key project goals related to stakeholder involvement and scenario development, the RIVERTWIN integrated model is being developed and tested in the well-monitored Neckar River basin in southwest Germany. Following model adjustment to Neckar River basin conditions, this model will be applied to the Ouémé basin in Benin and the Chirchik basin in Uzbekistan.

The consortium is creating an integrated model called Model for Sustainable Development of Watersheds (MOSDEW). MOSDEW connects a GIS-based user interface and database to external submodels. These submodels are used to support scenario runs and are more or less tightly coupled. In the case of the hydrological model, this means that input data is provided by a statistical downscaling technique combined with External Drift Kriging (Ahmed and de Marsily, 1987) and a regional soil and land use database information system. Therefore, the hydrological model simulates spatially distributed groundwater recharge that serves as boundary condition for the groundwater model which returns the baseflow in the channel network for re-use in the flood routing module. This integration defines specific requirements of the models used and will be discussed briefly. In addition, more information is available from Gaiser (2005).

\section{Model description}

Hydrologic models need to fulfill specific criteria in order to evaluate river basin management plans in contrasting environments involving changing boundary conditions such as 


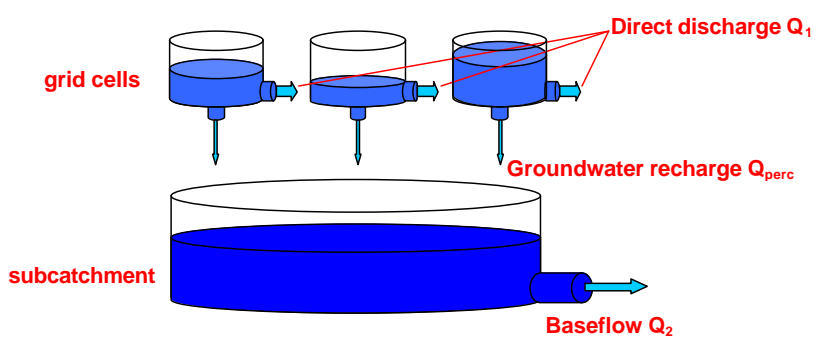

Fig. 1. Representation of the runoff concentration in the modified HBV model.

climate changes or policy interventions. The hydrologic model should be simple enough to work with large scales and sparse data and future climate scenarios. This is especially important for developing countries. At the same time, it should be based on reasonable representations of the dominant catchment processes and be able to reflect changes in catchment characteristics and forcing data. Therefore, a modified version of the semi-distributed conceptual HBV model (Bergström, 1995) has been used for the development of this model. The HBV model has conceptual routines for calculating snow accumulation and melt; soil moisture and runoff generation; runoff concentration within the subcatchment; and flood routing of the discharge in the river network. The snow routine uses the degree-day approach. Soil moisture is calculated by balancing precipitation and evapotranspiration using field capacity and permanent wilting point as parameters. Runoff generation is simulated by a nonlinear function of actual soil moisture and precipitation. The runoff concentration is modeled by two nonlinear reservoirs representing the direct discharge and the groundwater response. Flood routing between the river network nodes uses the Muskingum method. Additional information about the HBV model can be found in Uhlenbrook et al. (2004) and Hundecha and Bárdossy (2004).

\section{Overview of modifications}

The primary difference between the original HBV model and the modified version is the use of square grid cells as primary hydrological units having $1 \mathrm{~km}^{2}$ areas. This modification is necessary for two reasons: 1) All input data (precipitation and temperature) and catchment properties (e.g., soil and land use data) are calculated for the common model grid; and 2) To simulate the effects of changes in spatial land use patterns including the effects of a changed, but unknown distribution within a subcatchment.

\subsection{Fully distributed model version}

Due to the reasons described above, snowmelt, soil moisture, evapotranspiration and runoff concentration routines are calculated for each grid cell individually. The only exception is the runoff response which is represented conceptually
Table 1. Regionalized parameters and basis for regionalization.

\begin{tabular}{ll}
\hline Parameter & Regionalized by \\
\hline$k_{1}$ & Flow time, land use \\
$\alpha$ & Land use \\
$k_{\text {perc }}$ & Field capacity, wilting point \\
$S_{1}\left(t_{0}\right)$ & Soil class \\
\hline
\end{tabular}

by reservoirs for direct discharge and baseflow, respectively (Fig. 1). The groundwater reservoir is aggregated for the subcatchments because in a second step of model integration it is planned to replace this routine with the regional groundwater model. Despite the large number of parameters, this modified version is expected to give spatially more reasonable results than the original HBV model because the spatial distribution of the processes are taken into account rather than averaging over larger areas or elevation bands. Similar results were obtained by Uhlenbrook, et al. (2004). Notwithstanding, improved results are contingent on the accuracy of the input data.

\subsection{Parameter estimation by transfer functions}

The calibration parameters of the routines described above were estimated using transfer functions of catchment characteristics for two reasons: 1) Calibrating a model with a significant number of free parameters for every grid cell is not reasonable for meso-scale catchments; and 2) If the model is to reflect changes in catchment properties, then the parameters must be linked to natural qualities of the basin because calibration for future scenarios is not possible. Direct runoff, percolation from the grid cells and baseflow from each sub catchment is calculated using the following formulas.

$Q_{1}=k_{1} \cdot S_{1}^{1+\alpha}$
$Q_{2}=k_{2} \cdot S_{2}$
$Q_{\text {perc }}=k_{\text {perc }} \cdot S_{1}$

$Q_{i}$ is the discharge from the respective outlet of the reservoirs; $k_{i}$ and $\alpha$ are recession coefficients and exponent, respectively, and $S_{i}$ is the water level of the reservoirs. The model parameters, $p$, are expressed as transfer functions of catchment characteristics:

$p=G \quad$ (flowtime, landuse, soilcharacteristics)

Regionalization was initially completed by assuming linear relationships between model parameters and transfer function parameters. The model was then calibrated by adjusting the parameters of the transfer functions instead of the model parameters following the method proposed by Hundecha and Bárdossy (2004). Table 1 shows the combinations of catchment characteristics and model parameters used for calibration. 


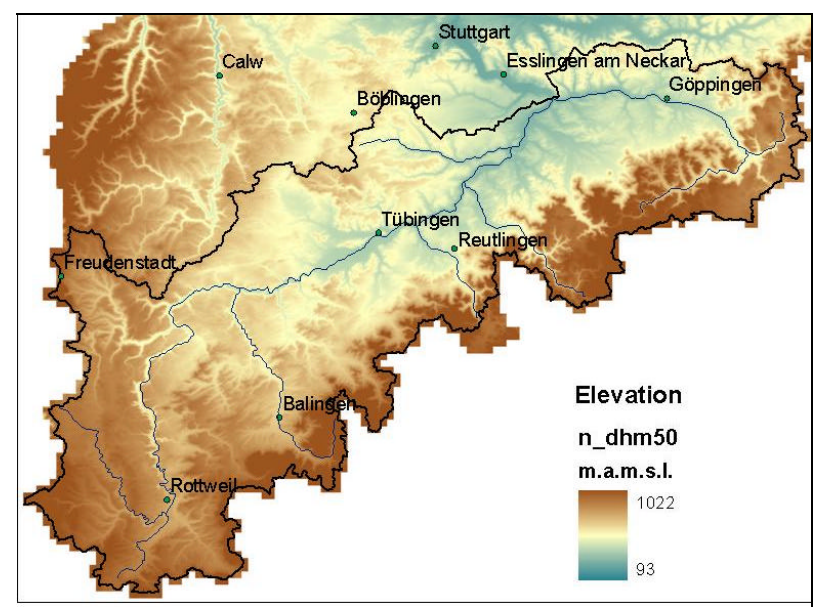

Fig. 2. Elevation and cities in the upper Neckar catchment.

Other parameters like the degree-day factor, threshold temperature, and additional evapotranspiration are held constant throughout the study area. Soil parameters (field capacity, permanent wilting point and the exponent beta of the soil moisture-runoff-relationship) are calibrated directly for the five soil classes identified in the catchment. Automatic calibration was accomplished using simulated annealing (Bárdossy, 1998) maximizing an objective function composed of Nash-Sutcliffe efficiencies having multiple temporal aggregation scales. Thus, a more detailed and realistic representation of the underlying physical processes is achieved with less free calibration parameters than a lumped model approach.

\section{Preliminary results}

The described methodology was tested for the central European upper Neckar basin up to the gauge Plochingen (Fig. 2) by calibration of the transfer functions for the headwater subcatchment of Rottweil and following transfer to the other subcatchments. Landuse (Landsat 1993, resolution $30 \mathrm{~m}$ ), soil (Bodenübersichtskarte 200, scale 1:200 000) and topographic data (resolution $50 \mathrm{~m}$ ) were aggregated to the common project raster $(1 \mathrm{~km})$. Precipitation and temperature data for model input was interpolated from observation station data. Discharge data from 13 gauging stations was used for model evaluation. All data was provided by the State Institute for Environmental Protection Baden-Württemberg.

The discharge from Plochingen and most tributaries can be reproduced with encouraging accuracy (Figs. 3 and 4). NashSutcliffe model efficiencies in the 13 subcatchments varied between 0.16 and 0.81 .

Because a meaningful simulation of the areal groundwater recharge is a prerequisite for consistent groundwater modeling, the results are compared to recharge simulations of the State Institute for Environmental Protection Baden-

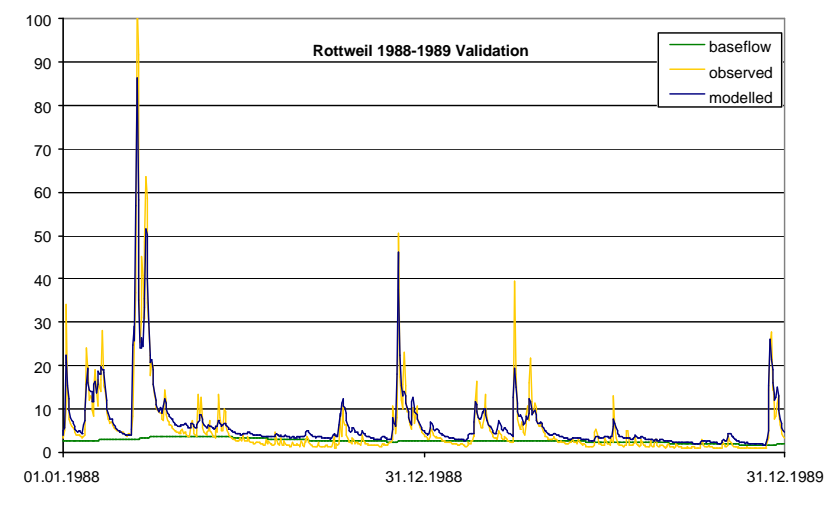

Fig. 3. Discharge at Rottweil in $\mathrm{m}^{3} / \mathrm{s}$ (calibration station, validation period).

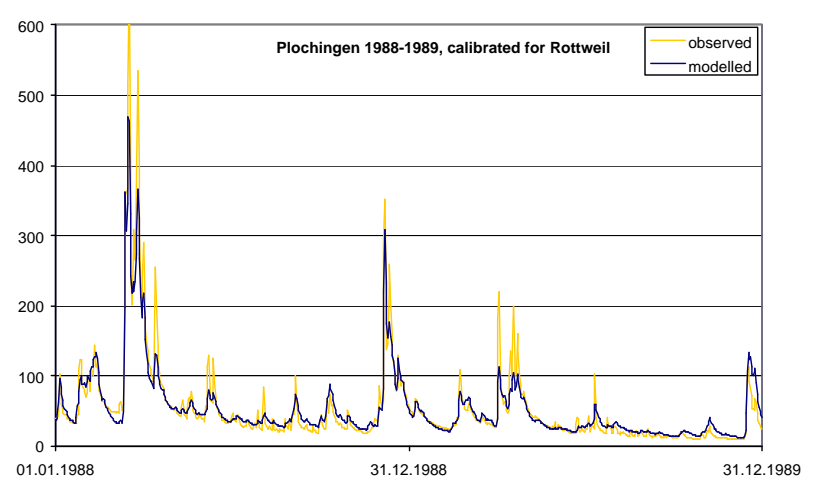

Fig. 4. Discharge at Plochingen in $\mathrm{m}^{3} / \mathrm{s}$ (not calibrated, transfer functions used).

Württemberg (LfU) using a method proposed by Armbruster (2002) (Fig. 5).

The annual average of 30 years of modeled groundwater recharge of the LfU and HBV simulations show similar means, $175 \mathrm{~mm}$ and $207 \mathrm{~mm}$, and standard deviations, $107 \mathrm{~mm}$ and $108 \mathrm{~mm}$, respectively. The correlation coefficient (0.44) for the $1 \mathrm{~km}$ grid values indicates that although local variations from the different model approaches exist the large scale patterns are matched well (aggregated $25 \mathrm{~km}^{2}$ grid cells: $r=0.7$ ). The map of deviations for the two methods shows that the modified HBV model overestimates groundwater recharge on the northern foothills of the Swabian Alb and underestimates percolation on the leeside of the Black Forest and in river valleys as compared to Armbruster (2002) (Fig. 6). This is due to the fact that the geology is not considered in the parameter estimation and the large resolution of $1 \mathrm{~km}^{2}$ can not resolve small scale features like alluvial valleys. Furthermore, experience in the LfU showed that the rainfall correction implemented in the Armbruster model may not be as reliable as expected. It should be noted that the HBV model was not calibrated to fit these values; rather they are used to asses the value of simulations associated with large scale groundwater modeling. 

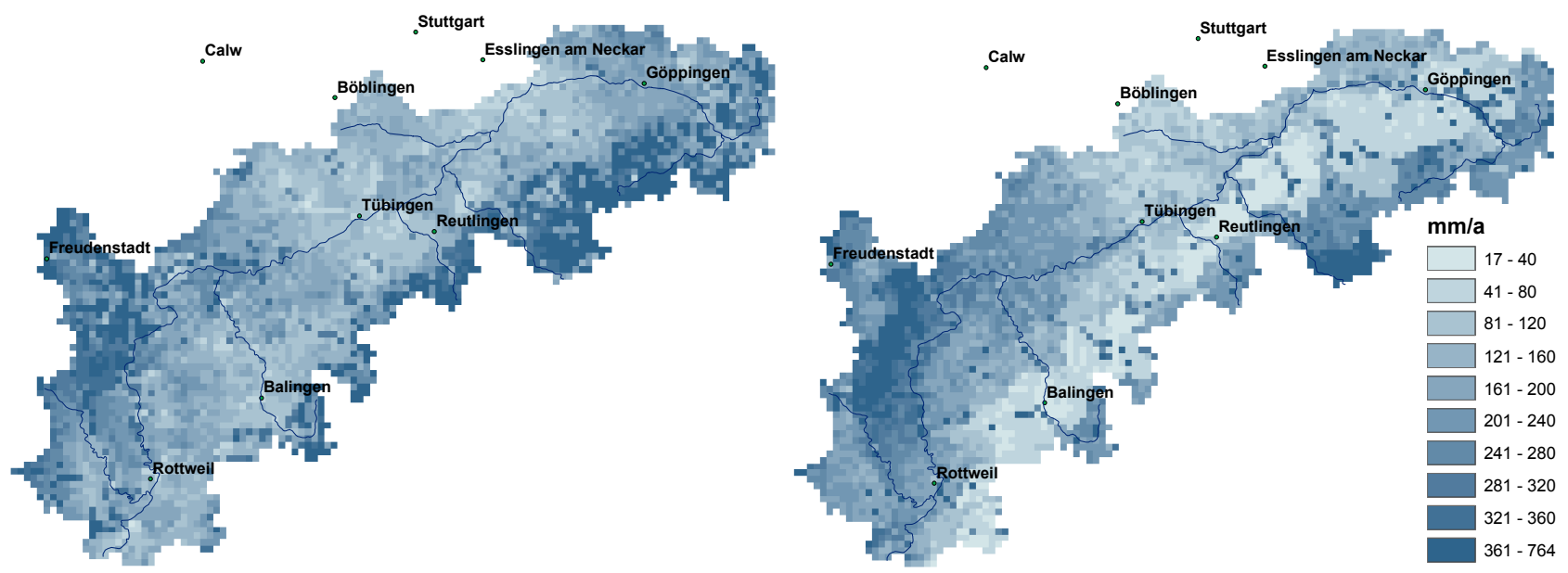

Fig. 5. Groundwater recharge simulated by the modified HBV (left) and LfU models (right).

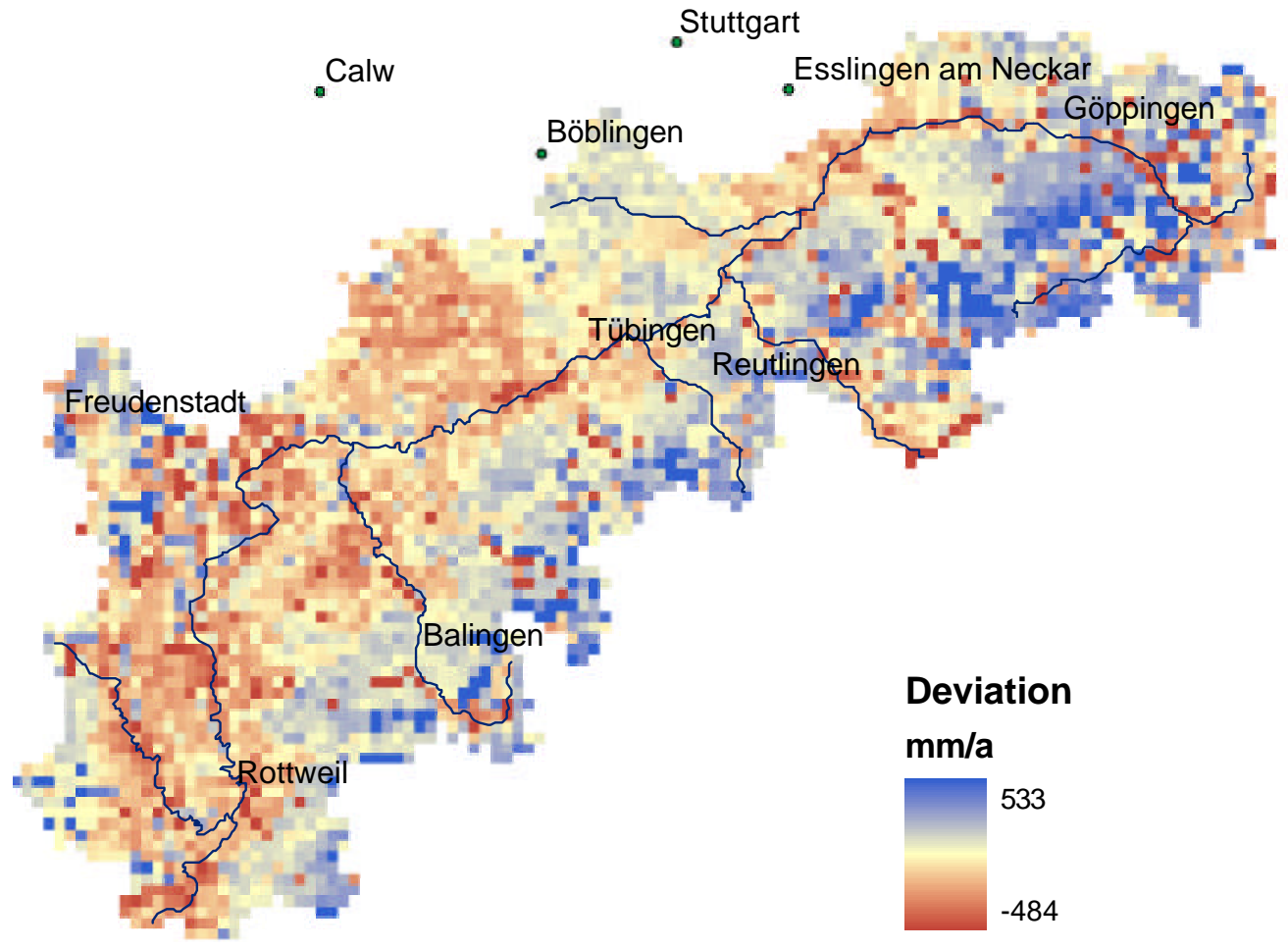

Fig. 6. Bias of groundwater recharge modeling of HBV from the LfU simulations.

These comparisons show that the conceptual model is a grey-box rather than a black-box description and that some physical meaning can be assigned to the modeled state variables and fluxes. This is important for reasonable coupling of the models and improves the ability to model changes in the basin.

\section{Conclusions}

The application of a modified version of the conceptual rainfall runoff model HBV to a mesoscale catchment produced the following conclusions: 1) The model can be modified to facilitate the coupling to a groundwater model. 2) The parameters can be regionalized using transfer functions defined a priori which means that it can also be used in ungauged catchments with similar hydrologic characteristics. 3) The areal groundwater recharge can be simulated reasonably well for the purpose of river basin management. 
The described methodology is currently being tested for the entire Neckar basin. After appropriate adjustment to the data situation and general framework, it will be used in the Ouémé basin in Benin and the Chirchik basin in Uzbekistan. In addition, scenarios in which climate change is considered have been developed and will be simulated with the integrated model to support the stakeholder interaction process.

Acknowledgements. This work was funded by the European Union in the Sixth Framework Program through the project RIVERTWIN. The valuable suggestions of $B$. Schaal and two anonymous reviewers are greatly appreciated.

Edited by: P. Krause, K. Bongartz, and W.-A. Flügel

Reviewed by: anonymous referees

\section{References}

Ahmed, S. and de Marsily, G.: Comparison of geostatistical methods for estimating transmissivity using data on transmissivity and specific capacity, Water Resour. Res., 23 (9), 1717-1737, 1987.

Armbruster, V.: Grundwasserneubildung in Baden-Württemberg, Freiburger Schriften zur Hydrologie (17), Institut für Hydrologie, Freiburg, 2002.

Bárdossy, A.: Generating precipitation time series using simulated annealing, Water Resour. Res., 34, 1737-1744, 1998.

Bergström, S.: The HBV model, in: Computer Models of Watershed Hydrology, edited by: Singh, V. P., Water Resources Pub., Littleton, CO, 443-476, 1995.

Gaiser, T.: RIVERTWIN - a Regional Model for Integrated Water Management in Twinned River Basins, http://www.rivertwin.de/, 2005.

Hundecha, Y. and Bárdossy, A.: Modeling of the effect of land use changes on the runoff generation of a river basin through parameter regionalization of a watershed model, J. Hydrol., 292, 281-295, 2004.

Uhlenbrook, S., Seibert, J., Leibundgut, C., and Rohde, A.: Prediction uncertainty of conceptual rainfall-runoff models caused by problems in identifying model parameters and structure, Hydrological Sciences Journal, 44(5), 779-797, 2004. 